\title{
The effect of daily consumption of different doses of fortified Lavash bread versus plain bread on serum vitamin-D status, body composition, metabolic and inflammatory biomarkers, and gut microbiota in apparently healthy adult: study protocol of a randomized clinical trial
}

Hadith Tangestani ${ }^{1}$, Kurosh Djafarian ${ }^{2}$ and Sakineh Shab-Bidar ${ }^{1 *}$

\begin{abstract}
Background: Due to the high prevalence of vitamin-D deficiency worldwide and its health consequences, intervention studies at the community level are warranted. The present study has been conducted to evaluate the effectiveness of vitamin-D-fortified bread on serum vitamin-D levels, inflammatory and metabolic biomarkers, and gut microbiota composition in vitamin-D-deficient individuals.

Methods/design: A double-blind, randomized controlled clinical trial is conducted on apparently healthy individuals with vitamin-D deficiency. The random allocation is done to divide participants into intervention groups including daily intake of vitamin-D-3-fortified bread (FB) with $500 \mathrm{IU} / 100 \mathrm{~g}$ bread $(n=30)$, FB with $1000 \mathrm{lU} / 100 \mathrm{~g}$ bread $(n=30)$, and 100 $g$ plain bread (PD) $(n=30)$. At baseline and after 3 months of the intervention period, blood, stool, and urine samples are taken. Anthropometric measures, body composition, blood pressure, and dietary assessment are made. The gut microbiome composition is measured by the 16S rRNA approach. Data is analyzed by SPSS software version 21.
\end{abstract}

Discussion: This study may partly explain for the first time the conflicting results from recent critical and systematic reviews regarding the role of vitamin $\mathrm{D}$ in microbiota composition.

Trial registration: Iranian Registry of Clinical Trials (IRCT), ID: IRCT20170812035642N3. Registered on 11 March 2018; http://www.irct.ir/user/trial/28134/view.

Keywords: Vitamin D, 25(OH) D, Fortified bread, Fortification, Vitamin-D deficiency, Fortified food

\footnotetext{
* Correspondence: s_shabbidar@tums.ac.ir

${ }^{1}$ Department of Community Nutrition, School of Nutritional Sciences and

Dietetics, Tehran University of Medical Sciences (TUMS), No 44, Hojjat-dost

Alley, Naderi St., Keshavarz Blvd, Tehran, Iran

Full list of author information is available at the end of the article
}

(c) The Author(s). 2019 Open Access This article is distributed under the terms of the Creative Commons Attribution 4.0 International License (http://creativecommons.org/licenses/by/4.0/), which permits unrestricted use, distribution, and reproduction in any medium, provided you give appropriate credit to the original author(s) and the source, provide a link to the Creative Commons license, and indicate if changes were made. The Creative Commons Public Domain Dedication waiver (http://creativecommons.org/publicdomain/zero/1.0/) applies to the data made available in this article, unless otherwise stated. 


\section{Background}

Vitamin-D deficiency is one of the most important public health concerns worldwide. According to epidemiological maps in many parts of the world, about half of the population has insufficient serum levels of vitamin D due to insufficient exposure to sunlight and lack of dietary intake [1]. According to recently published data from Iranian National Food and Nutrition Surveillance, over 90\% of the Iranian population have an undesirable serum level of vitamin D [2]. Vitamin D was taken into consideration because of its role in calcium-phosphorous and bone metabolism [3]. Thereafter, it became clear that inadequate vitamin $\mathrm{D}$ is associated with numerous pathological conditions such as autoimmune diseases like multiple sclerosis [4], type 1 diabetes [5], cancer [6], and even infectious diseases $[7,8]$. The role of vitamin $D$ in many tissues is known by its specific receptor, vitamin-D receptor (VDR). For example, the presence of VDR in immune system cells reflects the role of vitamin D in intestinal homeostasis and immunity [9].

The human gut is host for more than $10^{14}$ microorganisms, which are known as intestinal microbiota. These microorganisms play an effective role in obtaining nutrients, producing vitamins and destroying toxins by coexistence with the host $[10,11]$. The intestinal microbiota is also effective in controlling pathogens [12], regulating intestinal immunity [13], and host metabolism $[14,15]$. Based on previous studies, some of the factors affecting microbiome colonization, includes diet [16-18], host genetics [19], the environment [20], and medications such as antibiotics and laxatives [21].

Recently, a hypothesis has been suggested that vitamin$\mathrm{D}$ deficiency can alter the composition of intestinal bacteria. A recently published observational study has shown a link between dietary intake of vitamin D and intestinal bacteria [22]. In mouse models, it has also been observed that vitamin $\mathrm{D}$ can alter the intestinal microbiota population into a beneficial bacterium [23]. It also seems that vitamin $\mathrm{D}$ plays a role in regulating the immune system in the gut, and its deficiency may change the function of the intestinal wall, leading to transfer of endotoxins, like lipopolysaccharides (LPSs), into the bloodstream, which itself causes the development of inflammation [24]. Animal studies have also shown that vitamin D reduces dysbiosis, infection, permeability of the intestinal epithelial duct and ultimately deacreases the incidence of inflammatory bowel diseases, like Crohn's disease, by maintaining the hemostasis of the intestinal epithelium cells and tight-junction structures [23, 25, 26].

Vitamin D level is largely dependent on exposure to ultraviolet sun rays (wave-length of $290-315 \mathrm{~nm}$ ). However, various environmental, cultural, social, and individual factors can affect the amount of ultraviolet B (UVB) that reaches the skin. On the other hand, dietary sources of vitamin $\mathrm{D}$ are too rare. Therefore, supplementation and fortification are the only ways to achieve the amount of vitamin D required. Supplement consumption is challenged because of population coverage, people's compliance, cost, and regular consumption of supplements [27]. In contrast, using fortified foodstuffs has the advantage of lower cost and higher compliance [28]. Then, vitamin-D fortification seems to be a better startegy to prevent or treat vitamin-D deficiency. In this study we will fortify bread with vitamin $\mathrm{D}$, because it is available to people with moderate to severe food-insecurity households and its use is not significantly related to socioeconomic factors such as income and education. Also, according to the latest survey of the national food pattern in Iran, the average consumption of bread is more than $300 \mathrm{~g}$ per day,while milk intake,another current food that is fortified, is only $38 \mathrm{~g}$ per day [29]. In addition, bread is a staple food which is consumed routinely in all meals by the Iranian population.

Considering the high prevalence of vitamin-D deficiency in Iran [30], and its contribution to chronic diseases [31], using a fortified food, such as vitamin-D3-fortified bread, if proved to be effective in this study, can be encouraged as a preventive tool. Moreover, studies on the role of vitamin D in the human intestinal microbiota are rare. Therefore, this study has been designed to test the effectiveness of vitamin-D-fortified bread on serum vitamin-D levels, inflammatory and metabolic biomarkers, and gut microbiota composition in vitamin-D-deficient individuals.

\section{Specific aim}

The main aim of this study is to determine the effect of daily consumption of vitamin-D3-fortified bread on serum vitamin-D status, body composition, metabolic and inflammatory biomarkers, and gut microbiota in apparently healthy adults.

\section{Primary objective}

To compare within- and between-group variations in circulating $25(\mathrm{OH})$ D levels.

\section{Secondary objectives}

To compare within- and between-group variations in anthropometric, metabolic, inflammatory and oxidative stress biomarkers and gut microbiota

\section{Hypotheses}

(1) Daily consumption of vitamin- D3-fortified -bread improves serum 25(OH) D levels in apparently healthy subjects.

(2) Daily consumption of vitamin- D3-fortified -bread improves the biomarkers of anthropometric, 
metabolic, inflammatory, and oxidative stress and gut microbiota in apparently healthy subjects.

\section{Methods/design Design}

This is a 3-month, double-blind, randomized controlled clinical trial (RCT) in which apparently healthy subjects aged $20-60$ years are enrolled (Fig. 1).

\section{Ethics, consent, and permissions}

Tehran University of Medical Sciences will provide financial support for the current project. The trial will be conducted in compliance with the Declaration of Helsinki. The trial has received ethical approval from the Ethics Committee of Tehran University of Medical Sciences (number 96-02-161-35097). The current protocol is version 1, dated 31 January 2017, and any changes to the protocol will be communicated to all relevant parties, including participants.

\section{Participant recruitment}

In this trial, we will recruit a total of 90 participants (each group 30 subjects) from apparently healthy subjects of Tehran, the capital city of Iran. Participant recruitment was expected to commence by September 2018, and the trial is due to last 20 months. This assumes 4 months for participants recruitment, 4 months for run-in periods and intervention, 2 months for laboratory testing, 2 months for data collection, preparing and entering into SPSS software, 3 months for data retrieval and analysis, and 4 months to write the study report. A Standard Protocol Items: Recommendations for Interventional Trials (SPIRIT) Checklist [32] was used to report this protocol (Additional file 1, SPIRIT Checklist). Table 1 also shows the trial schedule. Before collecting any information, informed consent will be obtained from all participants. After reviewing the consent forms and answering any probable questions by study staff, those who are interested will be asked to sign the forms. A copy of the consent form will be gave to participants and all original signed consent forms will be kept by the study staff (Additional file 2, consent form).

\section{Eligibility}

The inclusion criteria for subjects include (1) having vitamin-D deficiency (<50 nmol/L), (2) no intake of supplements containing vitamin $\mathrm{D}$ or fish oil during the last 3 months, (3) not having clinical signs of diseases that interfere with vitamin-D metabolism (liver and kidney disease), and (4) not receiving any medications that interfer with the metabolism of vitamin $\mathrm{D}$ (corticosteroids, estrogen). Exclusion criteria include (1) any disease, or the need to use medication, which interferes with vitamin-D metabolism, (2) pregnancy or breastfeeding, and (3) any weight-loss treatments. Research participants can leave the study whenever they want.

\section{Setting}

The subjects will be recruited from the community by advertisements and notices, advertisements posted in public places, etc. For those who are interested in participating in the trial, study staff will confirm potential interest and eligibility of volunteers. Then, they will be reffered to a laboratory to identify subjects with vitamin$\mathrm{D}$ deficiency. If they have the requirement criteria and express an interest to collaborate in the study, the appointment will be set for their first visit. At the first visit, the potential participants will have the proposals of the research project fully explained to them, and all interested participants will be asked to fill in the consent form. A general information questionnaire, including demographic information, disease history, type and amount of medicine used, occupation, smoking status, a sun-light exposure questionnaire, Physical Activity Questionnaire (PAQ), and a food recall questionnaire will be completed for each participant.

\section{Sample size}

Based on data on serum $25(\mathrm{OH})$ D changes from Nikooyehet al [33]., to achieve $20 \mathrm{nmol} / \mathrm{L}$ difference in circulating 25(OH) D with a two-sided alpha of 0.05 and a beta of 0.2 after a 12-week intervention period, the target sample size will be 30 individuals per treatment group. We are not adjusting the primary outcome comparisons for the multiple pairwise comparison.

\section{Run-in}

Subjects with vitamin-D deficiency who are volunteering to participate in the study will be entered into the 2week maintenance weight program after the above steps have been taken. Subjects will be asked not to change their lifestyle and keep researchers informed of any changes including diet, physical activity, and medicine use. At the end of the first visit, a pamphlet will be given to the individuals, containing the description of the study, the description of the food groups, a date for the next visit, and the contact number. The presence of this run-in period is needed for maintening their weight, as well as to test the participants' motivation to continue the intervention.

\section{Randomization/blinding}

Those participants with vitamin- deficiency $(<50 \mathrm{nmol} / \mathrm{L})$ will be randomly assigned to receive either vitamin-Dfortified breads or plain bread. Randomization will be done using a computer-based random-digit generator. The allocation will be done in a 1:1:1 ratio. The research team, all participants, the staff involved in the clinical 


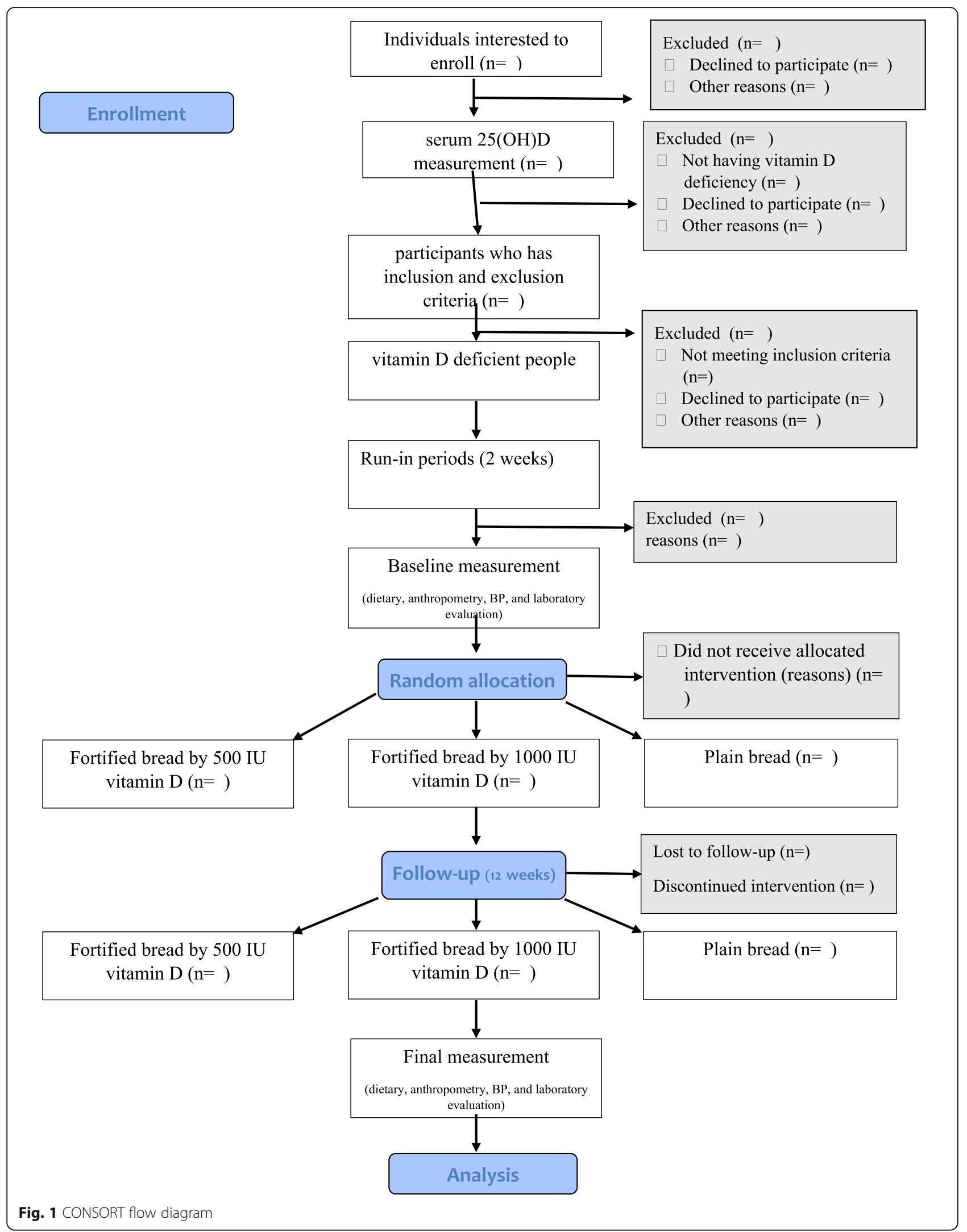


Table 1 Timetable of protocol

\begin{tabular}{|c|c|c|c|}
\hline \multicolumn{4}{|l|}{ Time table } \\
\hline ID: & Name: & $\begin{array}{l}\text { Sex: } \\
\text { Age : }\end{array}$ & Date: \\
\hline \multicolumn{4}{|c|}{$\begin{array}{ll}\text { Enrollment } \\
\end{array}$} \\
\hline \multicolumn{3}{|c|}{$\begin{array}{l}\text { First Call } \\
\text { Does participant have eligibility criteria to enter the study? } \\
\text { Yes } \square \text { No } \square\end{array}$} & Date: \\
\hline \multicolumn{3}{|c|}{$\begin{array}{l}\text { Vitamin D Deficiency Test } \\
\text { Is participant vitamin D deficient? } \\
\text { Yes No } \square\end{array}$} & Date: \\
\hline \multicolumn{4}{|c|}{ Run-in periods } \\
\hline \multicolumn{4}{|c|}{ Baseline measurement } \\
\hline \multicolumn{3}{|c|}{$\begin{array}{l}\text { Dietary assessment } \\
\text { 3-day recall } \square\end{array}$} & \multirow[t]{17}{*}{ Date: } \\
\hline Anthropomet & & & \\
\hline Height & weight & BMI & \\
\hline $\begin{array}{l}\text { Waist } \\
\text { circumference }\end{array}$ & Hip circumference & WHR ratio & \\
\hline \multicolumn{3}{|c|}{ Blood Pressure } & \\
\hline \multicolumn{3}{|c|}{$\begin{array}{l}\text { Body Composition Analysis } \\
\text { Body fat mass percentage } \\
\text { visceral fat percentage }\end{array}$} & \\
\hline \multicolumn{3}{|c|}{ Laboratory test } & \\
\hline \multicolumn{3}{|c|}{ Blood collecting } & \\
\hline CBC & total cholesterol & TG & \\
\hline LDL-C & HDL-C & FBS & \\
\hline ALT & AST & albumin & \\
\hline calcium & phosphorus & magnesium & \\
\hline zonulin & Serumlipopolysaccharide & & \\
\hline \multicolumn{3}{|l|}{ Urinary tests } & \\
\hline Calcium & phosphorus & magnesium & \\
\hline creatinine & microalbumin & & \\
\hline \multicolumn{3}{|l|}{ stool sample } & \\
\hline \multicolumn{4}{|c|}{ intervention } \\
\hline \multicolumn{3}{|l|}{ Bread receipt } & \multirow[t]{4}{*}{ Date: } \\
\hline First $2 \mathrm{WKs}$ & Second 2 WKs & Third 2 WKs & \\
\hline Forth 2 WKs & Fifth 2 WKs & Sixth 2 WKs & \\
\hline \multicolumn{3}{|c|}{ Final measurement } & \\
\hline \multicolumn{3}{|c|}{$\begin{array}{l}\text { Dietary assessment } \\
\text { 3-day recall } \square\end{array}$} & \multirow[t]{16}{*}{ Date: } \\
\hline \multicolumn{3}{|c|}{ Anthropometry } & \\
\hline height & weight & BMI & \\
\hline $\begin{array}{l}\text { Waist } \\
\text { circumference }\end{array}$ & Hip circumference & WHR ratio & \\
\hline \multicolumn{3}{|c|}{ Blood Pressure } & \\
\hline \multicolumn{3}{|c|}{$\begin{array}{l}\text { Body Composition Analysis } \\
\text { Body fat mass percentage } \\
\text { visceral fat percentage }\end{array}$} & \\
\hline \multicolumn{3}{|c|}{ Laboratory test } & \\
\hline \multicolumn{3}{|c|}{ Blood collecting } & \\
\hline $\mathrm{CBC}$ & total cholesterol & TG & \\
\hline LDL-C & HDL-C & FBS & \\
\hline$\overline{\mathrm{ALT}}$ & AST & albumin & \\
\hline Calcium & phosphorus & magnesium & \\
\hline zonulin & Serumlipopolysaccharide & & \\
\hline Urinary tests & & & \\
\hline Calcium & phosphorus & magnesium & \\
\hline creatinine & microalbumin & & \\
\hline
\end{tabular}

ALT alanine aminotransferase, AST aspartate aminotransferase, $B M I$ body mass index, CBC complete blood cell count, FBS fasting blood sugar, HDL-C high-density lipoprotein cholesterol, LDL-C low-density lipoprotein cholesterol, TG triglycerides, WHR waist to hip ratio center, and those assessing the outcomes and analyzing the data will be blinded to group assignment. Letter codes $\mathrm{A}, \mathrm{B}$, and $\mathrm{C}$ wil be used to identify the three groups, respectively. Breads will be packaged in identical color, size, and taste. Therefore, neither the participants nor the researchers, the interviewers or laboratory staff know which participants belong to which group,

\section{Intervention}

Breads will be either plain (PB; containing no vitamin D/ $100 \mathrm{~g}$ bread) or fortified with two different dosages of vitamin D3 (FB; containing $500 \mathrm{IU}$ vitamin D3/100 g bread or containing $1000 \mathrm{IU}$ vitamin $\mathrm{D} 3 / 100 \mathrm{~g}$ bread). Participants will receive a package of bread for both lunch and dinner. The timeframe for the intervention will be 12 weeks. Consumption of 1000 IU/day vitamin $\mathrm{D}$ is believed to be safe and effective to increase circulating 25(OH) D levels [34]. Participants will be given packages of bread for 2 weeks. All subjects will be visited biweekly to both assess their compliance and provide them with bread packages for the next 2 weeks.

\section{Compliance}

Participants will be asked to mark a reminder note for the daily consumption of bread. They will be given a sheet of paper that includes the code, the next visit date, two columns entitled "Lunch and dinner meals," and another column entitled "Date" to record their regular consumption of bread. Patients will beinstructed to attach the sheet on the refrigerator in order to remind them of their use of the bread. Volunteers will return the sheet every 2 weeks and they will be provided with a new, 2week, bread package.

\section{Patient and Public Involvement}

There is no involvement of patients or public in this study.

\section{Outcome measurements Dietary assessment}

A 3-day 24-h dietary recall questionnaire will be used to evaluate vitamin $\mathrm{D}$ and calcium intake. It includesd two work days and one weekend. Then, the data from questionnaire will be analyzed using N4 software (NUTRITIONIST 4, First Data Bank, San Bruno, CA, USA).

\section{Anthropometry measures}

The height will be measured without shoes by a stadiometer (Seca, Germany) with a sensitivity of $0.1 \mathrm{~cm}$ and weight with a digital scale (808 Seca, Germany) while wearing light clothes (with no coat or raincoat) with a sensitivity of $0.1 \mathrm{~kg}$. Body mass index (BMI) will be calculated by dividing the weight (in kilograms) by height squared (in meters). The waist circumference will be 
measured by a strip tape midway between the lowest rib and the iliac crest and during expiration. Then the waist to hip ratio (WHR) will be calculated for each person.

\section{Blood pressure}

Blood pressure (BP) will be measured twice for each person using a digital barometer (BC 08, Beurer, Germany) after at least $10-15 \mathrm{~min}$ of resting in a sitting position. Then, the average BP for each person will be calculated and recorded.

\section{Body composition analysis}

Body fat mass and visceral fat percentage will be measured by bioelectrical impedance analysis (Quadscan 4000 system, Bodystat, UK).

\section{Laboratory investigations Blood collecting}

A $20-\mathrm{mL}$ blood sample will be taken in a fasting state between 7:30 and 9:00 and stored in an acid-washed tube without anticoagulant. Then, after being stored at room temperature for $30 \mathrm{~min}$ and following blood clot formation, centrifugation at a speed of $1500 \mathrm{~g}$ for $20 \mathrm{~min}$ will be carried out. After that, the serum will be collected into separate micro-tubes and stored in a freezer at $-80^{\circ} \mathrm{C}$ freezer until laboratory analysis.

\section{Blood cell count}

A complete cell blood count $(\mathrm{CBC})$ will be measured by a blood-cell counter (Mythic, Orphee, France).

\section{Blood chemistry}

Fasting blood sugar (FBS) and lipid profile (total cholesterol, low-density lipoprotein cholesterol (LDL-C), highdensity lipoprotein cholesterol (HDL-C), and triglycerides (TG)) will be measured by enzymatic methods based on colorimetry using commercial kits (Pars Test, Iran) using the automatic device (Selecta E, Vitalab, The Netherlands). Alanine aminotransferase (ALT) and aspartate aminotransferase (AST) will be also be measured in the serum by enzymatic assays. Measurement of serum concentrations of albumin, calcium, phosphorus, and magnesiumwill be performed based on colorimetric method, using commercial kits (Pars Test, Iran) and an automatic device (Selecta E, Vitalab, The Netherland). These tests will be performed for all patients on the same day of blood sampling.

The serum level of $25(\mathrm{OH})$ D will be measured by high-performance liquid chromatography (HPLC). Serum intact parthyroid hormone (iPTH) level will be measured using commercial kits DRG (Frauenbergstrasse 18 D-35039 Marburg, Germany) and using the enzyme-linked immunosorbent assay (ELISA) method.

\section{Urinary tests}

Calcium, phosphorus, magnesium, and creatinine will be measured using the colorimetric method, and microalbumin by the immunoturbidometric method using commercial kits (Pars Test, Iran) and automatic devices (Selecta E, Vitalab, The Netherland).

\section{PBMC culture}

Peripheral blood mononuclear cells (PBMCs) were separated using Ficoll-hypaque gradient density centrifugation and cultured as described elsewhere [30], with minor modifications. In this study, $\sim 106$ cells will be transferred to a culture well in a six-well cell-culture plate (Greiner bio-one, Germany), each well containing $1 \%$ phytohemmaglutinin (PHA) (Gibco), $100 \mathrm{ng} / \mathrm{mL}$ LPSs (Gibco, United States), $100 \mathrm{U} / \mathrm{mL}$ penicillin $\mathrm{G}$ and $10 \mathrm{ng} / \mathrm{mL}$ streptomycin (both from Sigma-Aldrich, United States) in a total volume of $2 \mathrm{~mL}$ RPMI 1640. PBMC culture is performed in triplicate.

\section{Cytokine assay}

Measuring the cytokines (serum highly sensitive Creactive protein (hs-CRP) concentration, interleukin 4 (IL-4), interleukin 6 (IL-6), interleukin 10 (IL-10), tumor necrosis factor- $\alpha$ (TNF- $\alpha$ ), and interferon gamma (INF$\gamma)$ ) will becarried out in the culture medium.

\section{Microbiota composition}

The stool sample will be collected at baseline and at the end of the intervention and 16S ribosomal RNA (16S $r R N A$ ) genes, sequenced using polymerase chain reaction (PCR), will be applied to determine intestinal microbiome genome.

\section{Gut permeability evaluation}

Serum zonulin will be measured by ELISA. Serum LPSs will be measured using the HEK-Blue LPS Detection Kit (Invivogen, San Diego, CA, USA).

\section{Safety procedures}

We will record and report all adverse events, and participants with abnormal research samples will be referred to a physician.

\section{Data collection and management}

Data from questionnaires will be collected by HT and two other trained questioners. The collected data will be reviewed by HT at the end of the day and, in the case of any discrepancies in data collection, the questioner will be mentioned to reduce bias.

\section{Statistical analyses}

Data analysis will be done using SPSS version 21 software. To describe the quantitative data, the mean and 
standard deviations will be used and to describe the qualitative data absolute and relative abundance will be used. To compare absolute or relative abundance the chi-square or Fisher's exact statistics will be used. As the data should compare groups, between groups, and between-group changes, and to reduce the probability of the error, an analysis of two-way variance with repeated measures will be used to explore the impact of time and time-group effects with adjustment using the Bonferroni post-hoc test. The effects of the intervention in each group were examined using the paired $t$ test versus the baseline values. Between-group comparisons were examined using analysis of variance (ANOVA) followed by a Bonferroni post-hoc analysis. Covariance analysis will be used to adjust the effects of confounding variables. The correlation between the three groups will be evaluated by Pearson (normal data distribution) or Spearman (abnormal distribution). The significance level in this study will be considered to be $p<0.05$.

\section{Discussion}

In the last decade, attention has widened to the intestinal microbiota as an overlooked system. The various roles of vitamin $\mathrm{D}$ in health and many of its receptors in every organ of the body, particularly the gut, has increased the probable role of the intestinal microbiota through vitamin-D-dependent pathways in health and disease. Therefore, vitamin-D deficiency seems to play a vital role in health due to its effect on this intestinal microbiota. Solving the vitamin-D-deficiency problem through fortification of foods is an efficient and economical solution. Fortification has long been considered as an optional and mandatory way to improve nutrient deficiencies in developed countries. Bread has a special place in the Iranian diet. It is a staple food eaten with every meal and is also economically accessible to all people in the community. Moreover, it is important to note that milk, which is frequently fortified in developed countries, is not a good carrier for fortification in Iran due to its low consumption by the Iranian people. This study was designed following two important goals; the first is the efficiency of vitamin-D-fortified bread in improving serum levels of vitamin $\mathrm{D}$ and the second one is to determine the effect of vitamin $\mathrm{D}$ on body composition, metabolic and inflammatory biomarkers, and gut microbiota in apparently healthy adults.

The current protocol has some strength including the randomized placebo-controlled clinical trial design that is the strongest empirical evidence of a treatment's efficacy and suitable for causal inferences. The second strength is the fortification of bread in two doses, which can more accurately reflect the treatment effects. Determining the role of vitamin $\mathrm{D}$ and intestinal microbiota also takes place for the first time in this study and can be considered as the third strongest point of this protocol. One of the limitations of this protocol is the inability to measure the total microbiota profile of the intestine due to lack of funding. In addition, our study is a shortterm study and requires more pilot studies to be carried out for community-based fortification. Moreover, our protocol is based on apparently healthy people and cannot be generalized to the patient's community.

\section{Trial status}

The current protocol is version 1, dated 31 January 2017. The recruitment process will start on 1 July 2018 and is estimated to last for 6 months.

\section{Supplementary information}

Supplementary information accompanies this paper at https://doi.org/10. 1186/s13063-019-3852-z.

Additional file 1. SPIRIT Checklist

Additional file 2. Consent form.

\section{Abbreviations}

ALT: Alanine aminotransferase; AST: Aspartate aminotransferase; BP: Blood pressure; BMI: Body mass index; $\mathrm{CBC}$ : Complete blood cell count; EDTA: Ethylene diamine tetra-acetate; ELISA: Enzyme-linked immunosorbent assay; FB: Vitamin-D-3-fortified bread; FBS: Fasting blood sugar; HDL-C: Highdensity lipoprotein cholesterol; HPLC: High-performance liquid chromatography; hs-CRP: Highly sensitive C-reactive protein; iPTH: Intact parathyroid hormone; IFN-gamma: Interferon-gamma; IL-4/IL-6/IL-

10: Interleukin 4/interleukin 6/interleukin 10; LPSs: Lipopolysaccharides; LDLC: Low-density lipoprotein cholesterol; N4: Nutritionist; PAQ: Physical Activity Questionnaire; PB: Plain bread; PBMC: Peripheral blood mononuclear cells; PCR: Polymerase chain reaction; PHA: Phytohemmaglutinin; RCT: Randomized controlled clinical trial; SPIRIT: Standard Protocol Items: Recommendations for Interventional Trials; TUMS: Tehran University of Medical Sciences;

TG: Triglycerides; TNF: Tumor necrosis factor; UVB: Ultraviolet B; VDR: VitaminD receptor; WC: Waist circumference; WHR: Waist to hip ratio; $16 S$ rRNA: $16 S$ ribosomal RNA

Acknowledgements

We thank the Arad Charta Company for providing fortified bread in two different doses.

Authors' contributions

SS-b designed the initial idea of this work, which was further developed by $\mathrm{HT}$ and $\mathrm{KDj}$. The greater part of the work is being done as PhD research by $\mathrm{HT}$ under the supervision of both SS-b and KDj. The manuscript has been read and approved by all authors.

\section{Funding}

This work was supported by TUMS (grant number 96-02-161-35097) and the bread packages (both plain and vitamin-D-fortified) will be dedicated to the project by Arad Charta Company.

\section{Availability of data and materials}

The datasets generated and/or analyzed during the current study are available from the corresponding author on reasonable request.

Ethics approval and consent to participate

This study protocol was ethically approved by the Ethics Committee of Tehran University of Medical Sciences (number 96-02-161-35097).

Consent for publication

Informed consent will be obtained from all participants. 


\section{Competing interests}

The authors declare that they have no competing interests.

\section{Author details}

'Department of Community Nutrition, School of Nutritional Sciences and Dietetics, Tehran University of Medical Sciences (TUMS), No 44, Hojjat-dost Alley, Naderi St., Keshavarz Blvd, Tehran, Iran. ${ }^{2}$ Department of Clinical Nutrition, School of Nutritional Sciences and Dietetics, Tehran University of Medical Sciences (TUMS), Tehran, Iran.

Received: 31 May 2018 Accepted: 25 October 2019 Published online: 27 December 2019

\section{References}

1. Holick MF. The vitamin D deficiency pandemic and consequences for nonskeletal health: mechanisms of action. Mol Aspects Med. 2008:29:361-8.

2. Nikooyeh B, Abdollahi Z, Hajifaraji M, Alavi-Majd H, Salehi F, Yarparvar AH, Neyestani TR. Vitamin D status, latitude and their associations with some health parameters in children: national food and nutrition surveillance. J Trop Pediatrics. 2016:63:57-64.

3. Steenbock $\mathrm{H}$. The induction of growth promoting and calcifying properties in a ration by exposure to light. Science (New York, NY). 1924;60:224-5.

4. Munger KL, Levin LI, Hollis BW, Howard NS, Ascherio A. Serum 25hydroxyvitamin D levels and risk of multiple sclerosis. Jama. 2006;296:2832-8.

5. Wolden-Kirk H, Overbergh L, Christesen HT, Brusgaard K, Mathieu C. Vitamin $D$ and diabetes: its importance for beta cell and immune function. Mol Cell Endocrinol. 2011;347:106-20

6. Zeeb H, Greinert R. The role of vitamin D in cancer prevention: does UV protection conflict with the need to raise low levels of vitamin D? Deutsches Ärzteblatt Int. 2010;107:638.

7. Cannell J, Vieth R, Umhau J, Holick M, Grant W, Madronich S, Garland C, Giovannucci E. Epidemic influenza and vitamin D. Epidemiol Infect. 2006; 134:1129-40.

8. Laaksi I, Ruohola J-P, Tuohimaa P, Auvinen A, Haataja R, Pihlajamäki H, Ylikomi T. An association of serum vitamin D concentrations $<40 \mathrm{nmol} / \mathrm{L}$ with acute respiratory tract infection in young Finnish men. Am J Clin Nutr. 2007:86:714-7.

9. Veldman CM, Cantorna MT, DeLuca HF. Expression of 1,25-dihydroxyvitamin D3 receptor in the immune system. Arch Biochem Biophys. 2000:374:334-8.

10. Nicholson JK, Holmes E, Kinross J, Burcelin R, Gibson G, Jia W, Pettersson S. Host-gut microbiota metabolic interactions. Science. 2012;336:1262-7.

11. O'Shea EF, Cotter PD, Stanton C, Ross RP, Hill C. Production of bioactive substances by intestinal bacteria as a basis for explaining probiotic mechanisms: bacteriocins and conjugated linoleic acid. Int J Food Microbiol. 2012;152:189-205

12. Lawley TD, Walker AW. Intestinal colonization resistance. Immunology. 2013;138:1-11.

13. Hooper LV, Littman DR, Macpherson AJ. Interactions between the microbiota and the immune system. Science. 2012;336:1268-73.

14. Gravitz L. Microbiome: the critters within. Nature. 2012;485:S12-3.

15. Tilg H, Moschen AR. Microbiota and diabetes: an evolving relationship. Gut. 2014; qutjnl-2014-306928

16. Halmos EP, Christophersen CT, Bird AR, Shepherd SJ, Gibson PR, Muir JG. Diets that differ in their FODMAP content alter the colonic luminal microenvironment. Gut. 2014; gutjnl-2014-307264.

17. David LA, Maurice CF, Carmody RN, Gootenberg DB, Button JE, Wolfe BE, Ling AV, Devlin AS, Varma Y, Fischbach MA. Diet rapidly and reproducibly alters the human gut microbiome. Nature. 2014;505:559-63.

18. Matijašić BB, Obermajer T, Lipoglavšek L, Grabnar I, Avguštin G, Rogelj I. Association of dietary type with fecal microbiota in vegetarians and omnivores in Slovenia. Eur J Nutr. 2014;53:1051-64.

19. Turnbaugh PJ, Hamady M, Yatsunenko T, Cantarel BL, Duncan A, Ley RE, Sogin ML, Jones WJ, Roe BA, Affourtit JP. A core gut microbiome in obese and lean twins. Nature. 2009;457:480-4.

20. Costello EK, Stagaman K, Dethlefsen L, Bohannan BJ, Relman DA. The application of ecological theory toward an understanding of the human microbiome. Science. 2012;336:1255-62.

21. Gorkiewicz G, Thallinger GG, Trajanoski S, Lackner S, Stocker G, Hinterleitner T, Gülly C, Högenauer C. Alterations in the colonic microbiota in response to osmotic diarrhea. PLoS One. 2013;8:e55817.
22. Luthold RV, Fernandes GR, Franco-de-Moraes AC, Folchetti LG, Ferreira SRG. Gut microbiota interactions with the immunomodulatory role of vitamin D in normal individuals. Metabolism. 2017;69:76-86.

23. Ooi JH, Li Y, Rogers CJ, Cantorna MT. Vitamin D regulates the gut microbiome and protects mice from dextran sodium sulfate-induced colitis. J Nutr. 2013;143:1679-86.

24. Caricilli AM, Picardi PK, de Abreu LL, Ueno M, Prada PO, Ropelle ER, Hirabara SM, Castoldi Â, Vieira P, Camara NO. Retraction: gut microbiota is a key modulator of insulin resistance in TLR 2 knockout mice. PLoS Biol. 2016;14: e1002479.

25. Assa A, Vong L, Pinnell LJ, Avitzur N, Johnson-Henry KC, Sherman PM. Vitamin D deficiency promotes epithelial barrier dysfunction and intestinal inflammation. J Infect Dis. 2014;210:1296-305.

26. Assa A, Vong L, Pinnell LJ, Rautava J, Avitzur N, Johnson-Henry KC, Sherman PM. Vitamin D deficiency predisposes to adherent-invasive Escherichia coliinduced barrier dysfunction and experimental colonic injury. Inflamm Bowel Dis. 2015:21:297-306.

27. Neuhouser ML. Dietary supplement use by American women: challenges in assessing patterns of use, motives and costs. J Nutr. 2003;133:1992S-6S

28. Horton S. The economics of food fortification. J Nutr. 2006:136:1068-71.

29. Kalantari N, Ghafarpour M, Houshiarrad A, Kianfar H, Bondarianzadeh D, Abdollahi M, Esmaili M. National comprehensive study on household food consumption pattern and nutritional status, IR Iran, 2001-2003: National Report; 2005. p. 1

30. Neyestani TR, Gharavi AA, Kalayi A. Selective effects of tea extract and its phenolic compounds on human peripheral blood mononuclear cell cytokine secretions. Int J Food Sci Nutr. 2009;60:79-88.

31. Wang H, Chen W, Li D, Yin X, Zhang X, Olsen N, Zheng SG: Vitamin D and chronic diseases. Aging and disease 2017;8:346

32. Moher D, Shamseer L, Clarke M, Ghersi D, Liberati A, Petticrew M, Shekelle P, Stewart LA. Preferred reporting items for systematic review and metaanalysis protocols (PRISMA-P) 2015 statement. Syst Rev. 2015;4:1.

33. Adams JS, Clemens TL, Parrish JA, Holick MF. Vitamin-D synthesis and metabolism after ultraviolet irradiation of normal and vitamin-D-deficient subjects. N Engl J Med. 1982;306:722-5.

34. Nikooyeh B, Neyestani TR, Zahedirad M, Mohammadi M, Hosseini SH, Abdollahi Z, Salehi F, Mirzay Razaz J, Shariatzadeh N, Kalayi A. Vitamin Dfortified bread is as effective as supplement in improving vitamin D status: a randomized clinical trial. J Clin Endocrinol Metab. 2016;101:2511-9.

\section{Publisher's Note}

Springer Nature remains neutral with regard to jurisdictional claims in published maps and institutional affiliations.

Ready to submit your research? Choose BMC and benefit from:

- fast, convenient online submission

- thorough peer review by experienced researchers in your field

- rapid publication on acceptance

- support for research data, including large and complex data types

- gold Open Access which fosters wider collaboration and increased citations

- maximum visibility for your research: over $100 \mathrm{M}$ website views per year

At BMC, research is always in progress.

Learn more biomedcentral.com/submissions 